J. Lake Sci. (湖泊科学) , $2007, \mathbf{1 9 ( 3 ) ~ : 2 5 0 - 2 5 4 ~}$

http:// www. jlakes. org. E-mail: jlakes@ niglas. ac.cn

(c) 2007 by Journal of Lake Sciences

\title{
淀山湖有色可溶性有机物的光谱吸收特性
}

\author{
宋玲玲 ${ }^{1}$, 仇雁邻 ${ }^{1}$, 张洪恩 ${ }^{1}$, 刘登国 ${ }^{2}$, 韩中豪 ${ }^{2}$, 赵建夫 ${ }^{1}$ \\ ( 1 : 同济大学长江水环境教育部重点实验室, 上海 200092 ) \\ $(2$ : 上海市环境监测中心水质监测室, 上海 200030$)$
}

摘 要: 探讨了淀山湖水体中有色可溶性有机物 (CDOM) 的光谱吸收特性, CDOM 与叶绿素 a、浊度和 COD 等水质参数的 关系, 以及不同波段范围内 CDOM 光谱吸收形状 (指数函数斜率 $S$ 值) 的变化. 结果表明: 淀山湖 CDOM 吸收系数不高, 在 $355 \mathrm{~nm}$ 波长处的吸收系数变化范围是 $6.95-10.28 \mathrm{~m}^{-1}$, 而且湖南区高于湖北区; CDOM 吸收系数和叶绿素 a、浊度、COD 等水质参数的相关性都不高, 证明湖中的 CDOM 主要来自于城镇生活污水和工业废水的排放; CDOM 吸收系数在 $300-$ $500 \mathrm{~nm}$ 范围内随着波长的增加呈指数递减, 超过 $500 \mathrm{~nm}$ 之后呈线性递减, 在 $300-500 \mathrm{~nm}$ 波段范围内指数函数的曲线斜 率 $\mathrm{S}$ 为 $11.7-14.8 \mu \mathrm{m}^{-1}$, 在 $501-750 \mathrm{~nm}$ 波段范围内波长每增 $1 \mathrm{~nm}, \mathrm{CDOM}$ 的吸收系数减小 $0.0021 \mathrm{~m}^{-1}$. 关键词: 有色可溶性有机物质; 光谱吸收系数; 淀山湖

\section{On the light absorption characteristics of colored dissolved organic matter in Lake Dianshan}

SONG Lingling ${ }^{1}$, QIU Yanling ${ }^{1}$, ZHANG Hongen ${ }^{1}$, LIU Dengguo ${ }^{2}$, HAN Zhonghao ${ }^{2} \&$ ZHAO Jianfu ${ }^{1}$

( 1 : Key Laboratory of Yangtze Aquatic Environment, Ministry of Education, Tongji University, Shanghai 200092,P. R. China )

(2:Water Environment Division, Shanghai Environmental Monitoring Center, Shanghai 200030,P. R. China)

\begin{abstract}
This paper focuses on the spectral absorption characteristic of colored dissolved organic matter ( CDOM) in Lake Dianshan, which is the source of Huangpu River in Shanghai. The relationships between CDOM and water quality parameters, including chlorophyll a (Chl. a), turbidity and chemical oxygen demand (COD) were investigated. Spectral absorption shapes in different bands were studied to find precise $S$ values (absorption spectrum slope coefficient). The results show that absorption coefficients of CDOM are not high, absorption coefficients at $355 \mathrm{~nm}$ range from 6.95 to $10.28 \mathrm{~m}^{-1}$ and absorption coefficients in the south lake is higher than that in the north lake. Corrections of CDOM and water quality parameters are not high, which show that CDOM mainly comes from urban sewage and industry wastewater. Spectral absorption coefficients of CDOM in the bands from $300 \mathrm{~nm}$ to 500 $\mathrm{nm}$ exponentially decrease with wavelength increasing while decrease linearly after $500 \mathrm{~nm}$. The $S$ values in the bands from $300 \mathrm{~nm}$ to $500 \mathrm{~nm}$ changes from $11.7 \mu^{-1}$ to $14.8 \mu^{-1}$. Absorption coefficients after $500 \mathrm{~nm}$ decrease $0.0021 \mathrm{~m}^{-1}$ per.
\end{abstract}

Keywords: Colored dissolved organic matter; spectral absorption coefficient; Lake Dianshan

有色可溶性有机物 (colored dissolved organic matter, CDOM), 又称黄色物质,由腐殖酸,芳烃聚合物等 一系列物质组成, 主要是土壤和水生植物降解的产物 ${ }^{[1]}$, 存在于所有水体中, 它是溶解性有机物质的重要 组成部分 ${ }^{[2]}$. 光学特性较为单一, 主要表现为吸收, 且在紫外和蓝光波段随波长的增加呈指数下降, 由于其 在蓝光波段的吸收跟叶绿素 $\mathrm{a}$ 吸收重叠 ${ }^{[3]}$, 会干扰水色遥感, 导致水色遥感中叶绿素 $\mathrm{a}$ 浓度被高估, 影响水 体的遥感反射比.

淀山湖处于黄浦江上游, 是上海水源保护地, 上游来水主要为太湖水. 由于太湖污染逐年加重, 加之淀

* 上海市科委 2004 年重大科技专项资助项目 (04DZ12028). 2006-05-29 收稿;2006-09-06 收修改稿. 宋玲玲, 女,1983 年生;E-mail: songlingling21@ yahoo. com. cn. 
山湖湖内渔业养殖等的影响, 淀山湖的水质在逐渐恶化, 尤其是氮、磷超标明显, 水体有富营养化趋势. 本 文以淀山湖湖水中的 CDOM 为研究对象, 重点探讨以下几个方面问题: (1) 淀山湖 CDOM 的浓度和空间分 布情况; (2) CDOM 的吸收系数和叶绿素 a(Chl. a)、COD、浊度等水质参数之间的相关性; (3) CDOM 光谱吸 收形状的变化.

\section{1 实验方法}

\section{1 采样时间和点位}

2006 年 3 月 3 日在淀山湖布设了 19 个点进行了样品的采集分析, 采样点位置见图 1. 其中采样点 1 是淀峰, 是黄浦江的最上游; 采样点 $10 、 11 、 12$ 和 14 是淀山湖主要河流入湖口; 从 7 到 11 的采样点位于江 苏境内,其他采样点都在上海境内.

\subsection{CDOM 光谱吸收系数和其他水质参数的测定方法}

1.2.1 CDOM 的光谱吸收系数 采用岛津 UV 2401 分光光度计测定通 过玻璃纤维滤膜 $(\mathrm{GF} / \mathrm{F})$ 后水样的吸光度, 然后根据(1) 式计算得到各 波长的吸收系数 ${ }^{[1]}$.

$$
a\left(\lambda^{\prime}\right)=2.303 D(\lambda) / r
$$

式中, $a\left(\lambda^{\prime}\right)$ 为波长 $\lambda$ 处未校正的吸收系数 $\left(\mathrm{m}^{-1}\right), D(\lambda)$ 为吸光度, $r$ 为光程路径 $(\mathrm{m})$.

由于过滤清液还有可能残留细小颗粒, 可能会引起散射, 为此做如 下散射效应校正 ${ }^{[4]}$ :

$$
a(\lambda)=a\left(\lambda^{\prime}\right)-a(750) \lambda / 750
$$

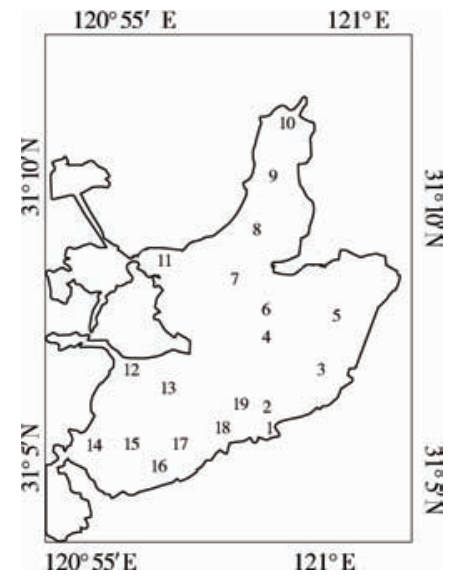

图 1 样点位置及湖底对遥感 反射率的影响区域分布

Fig. 1 Spatial distribution of samples in Lake Taihu

式中, $a(\lambda)$ 为校正后波长 $\lambda$ 处的吸收系数 $\left(\mathrm{m}^{-1}\right) ; a\left(\lambda^{\prime}\right)$ 为波长 $\lambda$ 处的未校正吸收系数 $\left(\mathrm{m}^{-1}\right) ; \lambda$ 为波 长 $(\mathrm{nm})$.

由于 CDOM 的浓度无法直接测定,最常用的方法是用 $355 \mathrm{~nm}$ 或者 $375 \mathrm{~nm}$ 等波长处的吸收系数来表示 CDOM 浓度. 为了方便和其他研究比较, 本文以 $355 \mathrm{~nm}$ 处的吸收系数表示 CDOM 的浓度.

1.2 .2 其他水质参数 叶绿素 $\mathrm{a}$ 采用分光光度法测定, 首先用 $0.45 \mu \mathrm{m}$ 的玻璃纤维滤膜过滤水样,然后用 $80 \%$ 的丙酮提取,最后用岛津 UV 2401 分光光度计测量其吸光度并计算. 浊度采用 WGZ - 1 数字式浊度仪 测定. COD 采用重铬酸钾法测量.

\section{1. $3 S$ 值的计算}

很多研究表明,CDOM 对 $500 \mathrm{~nm}$ 以下光谱的吸收基本上呈现指数衰减的规律, Bricaud ${ }^{[3]}$ 在 1981 年提 出如下的公式:

$$
a(\lambda)=a\left(\lambda_{0}\right) \exp \left[S\left(\lambda_{0}-\lambda\right)\right]
$$

式中, $a(\lambda)$ 是 $\mathrm{CDOM}$ 的吸收系数 $\left(\mathrm{m}^{-1}\right), \lambda$ 是波长 $(\mathrm{nm}), \lambda_{0}$ 是参照波长 $(\mathrm{nm})$, 一般取 $440 \mathrm{~nm}, S$ 是指 数函数曲线斜率参数,与有色可溶性有机物浓度无关,而与有色可溶性有机物的组成有关. 此外,采用波段 范围不同得到的 $S$ 值不同,通常采用最多的波段范围是 $300-500 \mathrm{~nm}$, 也有采用 $300-700 \mathrm{~nm}$ 更宽的范围. 为了得到更加可靠的 $S$ 值, 本文研究了在 $300-500 \mathrm{~nm} 、 501-750 \mathrm{~nm}$ 和上述整个波段范围内利用最小二乘 法进行曲线拟合的 $S$ 值.

\section{2 结果与讨论}

\subsection{CDOM 的光谱吸收特性和 CDOM 的空间分布}

图 2 给出了各采样站点 CDOM 的光谱吸收曲线. 由图可知,各点的吸收曲线表现出高度的一致性,在 紫外波段吸光度比较大,在可见光和红外波段吸光度明显变小,在 $750 \mathrm{~nm}$ 附近的近红外波段吸光度趋向 于 0 .

图 3 是 19 个采样点的水样在 $355 \mathrm{~nm}$ 波长处的吸收系数, 平均吸收系数为 $8.84 \mathrm{~m}^{-1}$, 范围在 $6.95-$ 
$10.28 \mathrm{~m}^{-1}$, 相对于 Tamiami 河流 ${ }^{[5]} \mathrm{a}(355)$ 的 $33.7 \mathrm{~m}^{-1}$, Orinoco 河流的 a(300) 的 $22.6-57.3 \mathrm{~m}^{-1}$, Surumoni 河流 $\mathrm{a}(300)$ 的 $14.7-151.1 \mathrm{~m}^{-1[6]}$, 可知淀山湖的 CDOM 浓度并不高.

此外, 根据图 3 吸收系数的大小, 在湖南区除了第 14 号点之外, 其他点水样的吸收系数相对于湖北区 较大, 在湖北区除了第 10 个点比较大之外, 其他采样点的吸光系数都比较小, 说明湖南区的 CDOM 浓度高 于湖北区.

\subsection{CDOM 的光谱吸收系数与叶绿素 $\mathrm{a} 、$ 浊度和 COD 之间的关系}

CDOM 能够吸收紫外线和低波段的可见光, 在紫外光光处有菼光现象, 影响叶绿素的遥感反演. 为了 便于对淀山湖不同采样点的 CDOM 吸收光谱进行比较, 找出影响 CDOM 光谱吸收系数的主要因素, 分别按 照式 (4) 和式 (5) 对吸收系数和叶绿素 a 含量进行标准化处理, 然后进行相关性分析 ${ }^{[7]}$.

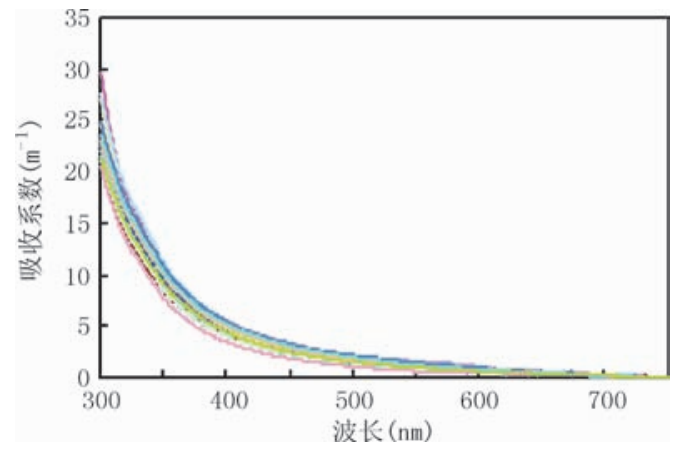

图 2 CDOM 吸收曲线

Fig. 2 Spectral absorption curves of CDOM

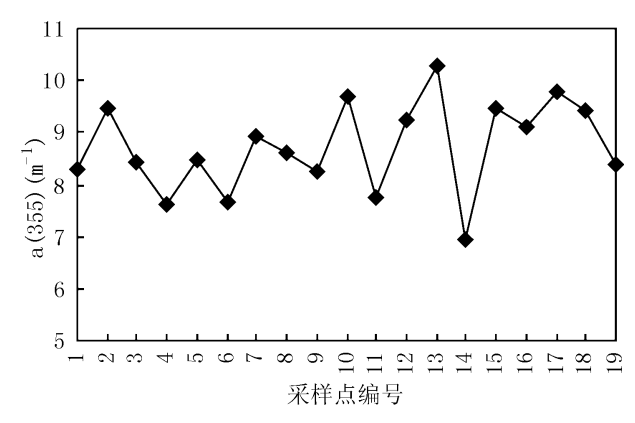

图 3 不同采样点在 $355 \mathrm{~nm}$ 处的吸收系数

Fig. 3 Absorption coefficients of $355 \mathrm{~nm}$ at different samples

$$
a^{*}(\lambda)=a(\lambda) / a(440)
$$

式中, $a(440)$ 是 $440 \mathrm{~nm}$ 处的吸收系数, $a(\lambda), a^{*}(\lambda)$ 分别为任意波长处的吸收系数和标准化吸收系数.

$$
C_{i}^{*}=\frac{C_{i}-\bar{C}_{i}}{S_{i}} ; S_{i}=\sqrt{\frac{\sum\left(C_{i}-\bar{C}_{i}\right)^{2}}{19-1}}
$$

式中, $C_{i}$ 是第 $i$ 个采样点处的水质浓度, $\bar{C}_{i}(i=1,2, \cdots, 19)$ 是 19 个采样点水质浓度的平均值, $S_{i}$ 是采样点水 质浓度的标准偏差.

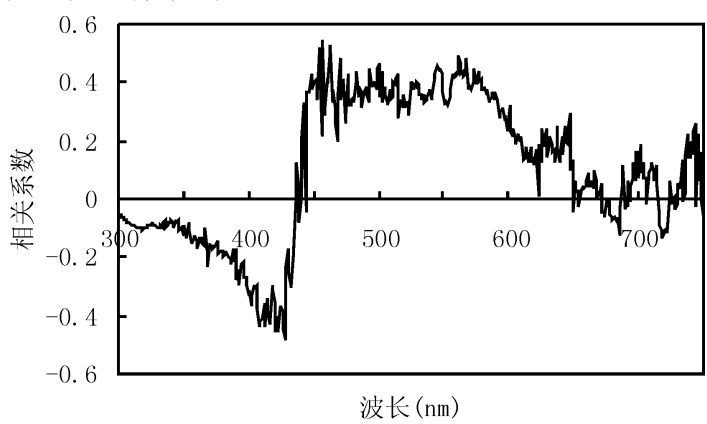

图 4 CDOM 吸收和 Chl. a 含量之间的相关性

Fig. 4 Correlation between absorption coefficients of CDOM and Chl. a concentration

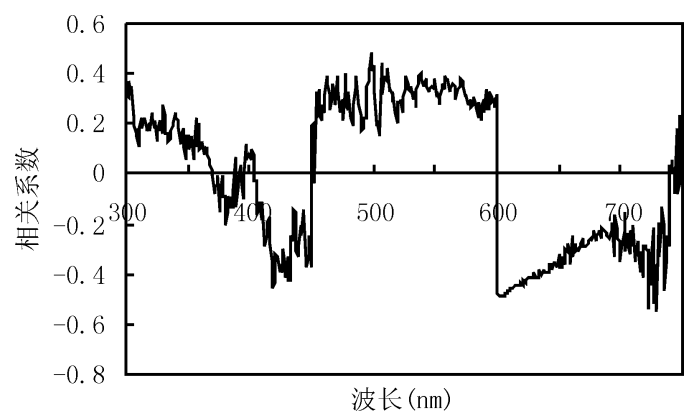

图 5 CDOM 吸收和 COD 之间的相关性

Fig. 5 Correlation between absorption coefficients of and COD

图 4 显示了 CDOM 吸收系数和 19 个采样点的叶绿素 $\mathrm{a}$ 的相关关系, 由图可知, 吸收系数与叶绿素 $\mathrm{a}$ 的 相关系数很小, 在 $420-440 \mathrm{~nm}$ 和 $450-575 \mathrm{~nm}$ 范围内的相关系数分别是 -0.4 和 0.4 左右, 其他范围内相 
关系数很小甚至基本上不存在相关性, 反映了在春季淀山湖中的 CDOM 主要来源不是浮游植物的自身降 解产物,而是河流和周围城镇居民的生活污水和工业废水.

图 5 表明了 CDOM 吸收系数和 COD 之间的相关性最高是在 $450-600 \mathrm{~nm}$ 波长范围内,相关系数在 0.3 左右, 相关性不显著. 相对于叶绿素 a 和 COD, CDOM 与浊度的相关性较高 (图 6), 特别是在 $600 \mathrm{~nm}$ 之后, 相关系数达到了 $0.6-0.7$, 二者呈一定的负相关.

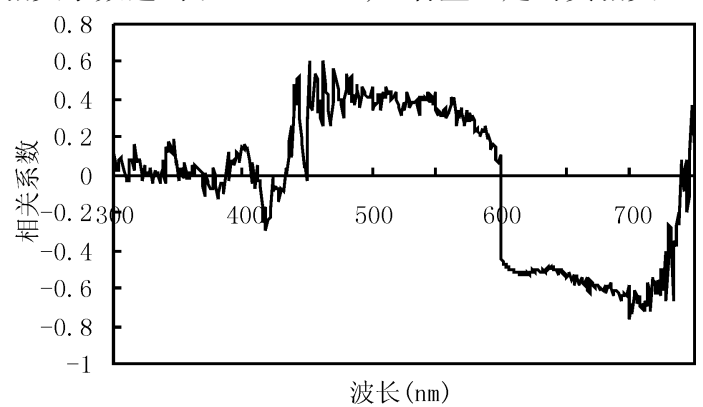

图 6 CDOM 吸收和浊度之间的相关关系

Fig. 6 Correlation between absorption coefficients of CDOM and turbidity

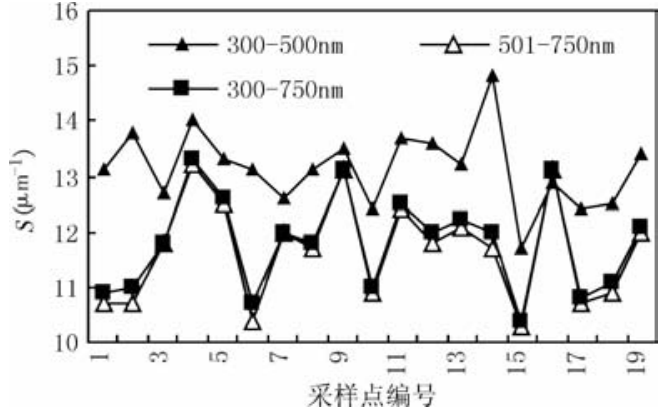

图 7 不同波段范围内的各点的 $S$ 值

Fig. $7 \mathrm{~S}$ values of all samples in different bands

\section{3 CDOM 的光谱吸收形状}

将测定的 $300-750 \mathrm{~nm}$ 波段范围的 CDOM 的吸收系数按式(3)进行拟合,得到不同波段范围内、不同 采样点的 $S$ 值 (图 7). 结果表明: (1) 同一样点、不同波长范围内的 $S$ 值差异较大, 最大相差 $3.10 \mu \mathrm{m}^{-1}$. $300-500 \mathrm{~nm}$ 范围内 $S$ 值变化范围为 $11.70-14.80 \mu \mathrm{m}^{-1}$, 平均为 $13.15 \mu \mathrm{m}^{-1}$;500 - $750 \mathrm{~nm}$ 范围内 $S$ 值 变化范围是 $10.30-13.20 \mu \mathrm{m}^{-1}$, 平均为 $11.68 \mu \mathrm{m}^{-1} ; 300-750 \mathrm{~nm}$ 范围内 $S$ 值变化范围为 $10.4-13.30$ $\mu \mathrm{m}^{-1}$, 平均为 $11.81 \mu \mathrm{m}^{-1}$. (2) Davies-Colley ${ }^{[8]}$ 曾对黄色物质浓度相差很大的 12 个内陆淡水湖泊进行研 究, 发现 $S$ 值变化不大,平均为 $18.7 \mu \mathrm{m}^{-1}$. Markager ${ }^{[9]}$ 用大量实测数据进行计算得到,淡水湖泊的 $\mathrm{S}$ 值在 $10-25 \mu \mathrm{m}^{-1}$ 之间, 平均值为 $17.7 \mu \mathrm{m}^{-1}$. 相对于国外研究, 淀山湖水体黄色物质的 $S$ 值偏低. (3) $300-$ $500 \mathrm{~nm}$ 范围内 $S$ 值和张运林 ${ }^{[9]}$ 研究发现太湖水在 $280-500 \mathrm{~nm}$ 范围内的 $S$ 值 $14.37 \mu \mathrm{m}^{-1}$ 接近. (4) $300-$ $750 \mathrm{~nm}$ 范围内的 $S$ 值和 $501-750 \mathrm{~nm}$ 的 $S$ 值相对于 $300-500 \mathrm{~nm}$ 范围内的 $S$ 值偏小, 而且二者比较相近, 这和张运林 ${ }^{[10]}$ 研究结论一致, 都是在低波段范围的 $S$ 值高于高波段的 $S$ 值, 高波段和全波段的 $S$ 值班比较 接近. 这说明方程式 (3) 只是对光谱曲线的近似描述,扩大波长范围会影响 $S$ 值的变化.

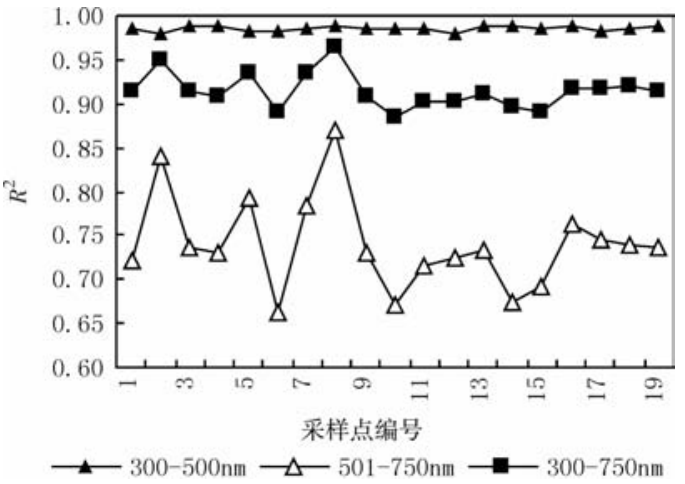

图 8 不同波段指数拟合时的 $R^{2}$

Fig. $8 R^{2}$ from exponential fitting in different bands

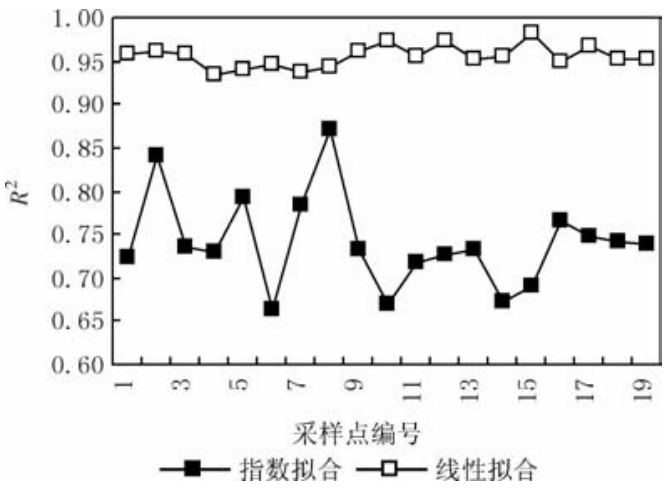

图 $9501-750 \mathrm{~nm}$ 范围不同拟合方法的 $R^{2}$ Fig. $9 R^{2}$ from different fitting method in $501-750 \mathrm{~nm}$

为了评价方程式 (3) 在不同波段范围的拟合精度, 计算拟合曲线的 $R^{2}$ (图 8 ), 结果表明: (1) 在 $300-$ 
$500 \mathrm{~nm}$ 范围内不同采样点处的 $R^{2}$ 差别很小, 都接近于 1 , 最小值是 0.9794 , 说明在此波段范围内的 $S$ 值具有 很高的可靠性, 式(3) 的拟合精度高, 在此波段范围内可以用式(3) 描述 CDOM 的吸收光谱曲线. (2) 501 $750 \mathrm{~nm}$ 范围内不仅不同采样点的 $R^{2}$ 差别很大, 而且比较低, 最大值是第 8 个采样点的 0.8708 , 最小值是第 6 个采样点的 0.6628 , 说明了在这个波段范围内的 $S$ 值不可靠, 吸收系数不是指数变化: 在此波段范围内不能 用式(3) 描述 CDOM 的吸收光谱曲线. (3) 整个 $300-750 \mathrm{~nm}$ 波段范围内的 $R^{2}$ 依然较高, 都在 0.90 左右, 不同采样点之间的 $R^{2}$ 波动也不大, 最大值和最小值差别只有 0.081 , 说明了在整个波段范围内的 $S$ 值具有 一定的可靠性,受 $501-750 \mathrm{~nm}$ 范围内的吸光系数影响较小.

图 9 对 $501-750 \mathrm{~nm}$ 波段范围的光谱曲线采用线性拟合和指数拟合进行精度评价, 从图上可以看出相 对于指数拟合, 利用线性拟合时 $R^{2}$ 比较高, 在 0.96 范围内, 波动也比较小, 进一步证实了在 $501-750 \mathrm{~nm}$ 范围内不能用方程式 (3) 描述 CDOM 的吸收光谱曲线,而应该用线性方程描述. 利用 $\lambda_{0}-\lambda$ 作自变量, $a$ $(\lambda) / a\left(\lambda_{0}\right)$ 为因变量作线性回归, 得到平均回归斜率为 $0.0021 \mathrm{~m}^{-1}$, 即波长每增加 $1 \mathrm{~nm}, \mathrm{CDOM}$ 的吸收系 数减少 $0.0021 \mathrm{~m}^{-1}$.

\section{3 结论}

(1) 淀山湖水体的 CDOM 吸收系数不高, 平均为 $8.84 \mathrm{~m}^{-1}$, 在 $355 \mathrm{~nm}$ 波长处的吸收系数变化范围是 $6.95-10.28 \mathrm{~m}^{-1}$, 且湖南区略高于湖北区.

(2) CDOM 吸收系数和叶绿素 a 和 COD 的相关性较小, 与浊度的相关性稍大, 说明湖水中的有机物主 要来自于城镇生活污水和工业废水的排放.

(3) CDOM 吸收曲线在 $300-500 \mathrm{~nm}$ 范围内随着波长的增加呈指数递减, 超过 $500 \mathrm{~nm}$ 之后呈线性递 减; 在 $300-500 \mathrm{~nm}$ 范围内指数函数的曲线斜率 $\mathrm{S}$ 在 $11.7-14.8 \mu \mathrm{m}^{-1}, R^{2}$ 最小值 $0.979, S$ 值的精度很高; 在 $501-750 \mathrm{~nm}$ 波段范围内波长每增 $1 \mathrm{~nm}, \mathrm{CDOM}$ 的吸收系数减小 $0.0021 \mathrm{~m}^{-1}$.

\section{4 参考文献}

[1] Kirk J T O. Light and photosynthesis in aquatic ecosystem. Cambridge: Cambridge University Press, 1994.

[2] Rochelle2Newall E J, Fisher T R. Chromophoric dissolved organic matter and dissolved organic carbon in Chesapeake Bay. Marine Chemistry ,2002, 77:23 - 41.

[3] Bricaud A, Morel A, Prieur L. Absorption by dissolved organic matter of the sea (yellow substance) in the UV and visible domain. Limnology and Oceanography, 1981,26:43 - 53.

[4] Keith D J, Yoder J A, Freeman S A. Spatial and temporal distribution of colored dissolved organic matter (CDOM) in Narragansett Bay, Rhode Island : implications for phytoplankton in coastal waters. Estuarine, Coastal and Shelf Science, 2002,55:705 - 717.

[5] Green S A, Blough N V. Optical absorption and fluorescence properties of chromophoric dissolved organic matter in natural waters. Limnology and Oceanography, 1994,39:1903 - 1916.

[6] Battin T. Dissolved organic matter and its optical properties in a blackwater tributary of the upper Orinoco River, Venezuela. Org Geochem, 1998,8:561 - 569.

[7] 马荣华, 戴锦芳等. 东太湖 CDOM 吸收光谱的影响因素与参数确定. 湖泊科学, 2005, 17 (2): 120 - 126 .

[8] Davis-colley R J. Absorption of light by yellow substance in freshwater lakes. Limnology and Oceanography, $1983,32(2): 416-425$.

[9] Markager W, Vincent W F. Spectral light attenuation and absorption of UV and blue light in natural waters. Limnology and Oceanography, 2000, 45(3):642 - 650 .

[10] 张运林,秦伯强等. 太湖典型草、藻型湖区有色可溶性有机物的吸收及菼光特性. 环境科学, 2005,26 (2) $: 142-147$. 